DOI 10.37882/2223-2982.2021.04.13

\title{
ДИСКУССИОННЫЕ ОСОБЕННОСТИ РЕЧЕВОГО ПОРТРЕТА СОВРЕМЕННОЙ ЖЕНЩИНЫ-ПОЛИТИКА В ГЕНДЕРНОМ АСПЕКТЕ
}

\section{DISCUSSIONAL FEATURES OF A SPEECH PORTRAIT OF A MODERN WOMAN-POLITICIAN IN A GENDER ASPECT}

\section{Du Shanshan}

Summary: Today, one of the main tools through which the image of a politician is constructed is the style of his speech communication. The features of the linguistic portrait of a person largely depend on gender characteristics that are assimilated in the process of a person's socialization and that influence the way he builds up verbal communication. In this article, the author analyzes the theoretical constructs and practical implementation of models of speech behavior of women politicians in the West, reveals the reasons for the use of gender stereotypes and tactics in speech, concludes on the importance of their influence on the formation of the political image of the communicator.

Keywords: speech portrait, linguistic features, woman politician, gender aspect, masculine features of the language.

\author{
Ду Шаньшань \\ Аспирант, Санкт-Петербургский государственный \\ университет \\ du.shanshan@bk.ru
}

Аннотация: На сегодняшний день одним из основных инструментов, посредством которого конструируется образ политика, является стиль его речевой коммуникации. Особенности лингвистического портрета личности во многом зависят от гендерных характеристик, усваиваемых в процессе социализации человека и оказывающих влияние на способы выстраивания им речевой коммуникации. В настоящей статье автор анализирует теоретические конструкты и практическую реализацию моделей речевого поведения женщин-политиков на Западе, вскрывает причины использования гендерных стереотипов и тактик в речи, делает вывод о значимости их влияния на формирование политического имиджа коммуникатора.

Ключевые слова: речевой портрет, лингвистические особенности, женщинаполитик, гендерный аспект, маскулинные особенности языка.
Л ичностные особенности каждого человека находят отражение не только в его внешнем облике, но также и в манере общения. Как отмечают Р.Ж. Саурбаев и Х.С. Шагбанова лингвистические средства являются тем инструментом, с помощью которого осуществляются речевые стратегии и тактики [5, с. 29]. Межличностная коммуникация в устной форме одновременно выступает как способ самовыражения личности, так и механизм воздействия на аудиторию. Ей свойственны определенные отличия по гендерному признаку, в частности, применение коммуникатором в речи устойчивого набора определенных шаблонных выражений. В настоящее время значимость изучения этих особенностей существенно повысилась вследствие возникновения и развития такого направления в языкознании как феминистская лингвистика, или феминистская критика языка.

Составление речевого портрета женщин-политиков и мужчин-политиков целесообразно осуществлять на базе анализа теоретических разработок ученых, занимавшихся исследованием данной проблемы, а также опираясь на опубликованные материалы выступлений, конференций, дебатов и проч. известных политических фигур, иными словами, на речевую практику. При этом теоретический аспект проблемы привлекал внимание исследователей с точки зрения частого использования конкретных частей речи (прилагательных, существительных и т.д.) в устной коммуникации как мужчинами, так и женщинами [4], соотношения стереотипов речевого поведения, механизмов выстраивания диалога. В комплексе они находят отражение в реальном практическом коммуникативном поведении, которое, с точки зрения И.А.Стернина, представляет собой «... совокупность норм и традиций общения народа, социальной, возрастной, профессиональной и других групп» [6, с.106].

Говоря о значимости опубликованных материалов, следует отметить, что гендерный аспект политической коммуникации прослеживается, в первую очередь, в СМИ, данные которых позволяют наилучшим образом проследить специфику исследуемых различий. Речь идет преимущественно о западных средствах массовой информации в силу того, что составление речевого портрета женщины-политика целесообразно производить на западных примерах (в частности, наиболее яркими и современными из них являются Х. Клинтон и А. Меркель), так как в Восточной Европе широкое участие женщин в политической жизни по-прежнему продолжает оставаться сравнительно редким явлением.

Исследование дискуссионных особенностей рече- 
вых портретов женщин именно в сфере политики определено не случайно. Традиционно данная область общественной жизни считается преимущественно «мужской», В которой способны реализовать свой потенциал немногие женщины. При этом, подобный подход, берущий свое начало еще в древности и базирующийся на выделении «женских» и «мужских» ролей в социуме, в настоящее время обретает новое звучание. Это объясняется тем, что в современных развитых странах господствует принцип гендерного равенства, накладывающий отпечаток на все стороны общественной жизни, в том числе - и на политику. Еще в начале XXI столетия дискуссии о гендере и власти в сфере политики приобрели особую остроту в мире [11, с. 321], которые вплоть до настоящего момента только продолжали актуализироваться, в особенности, в связи с постепенным увеличением доли женщин-политиков, баллотирующихся и избираемых в парламенты разных стран. Однако, декларируемое равенство вступает в противоречие с реальной политической практикой в силу того, что в настоящее время доля женщин в политическом сегменте продолжает оставаться незначительной [2, с. 247].

Таким образом, гендерные различия в политической сфере проявляются и сегодня, что накладывает существенный отпечаток на личностное становление женщин, избравших для себя карьеру политиков. Как политический лидер женщина вынуждена, с одной стороны, выстраивать новую, более жесткую, линию поведения, соответствующую практике преобладания мужчин в политике, что прослеживается в изменениях конструирования речевой коммуникации. С другой стороны, существуют примеры женщин-политиков, не пытавшихся соответствовать заданным стандартам данной области общественной жизни и не копирующих мужское поведение, что актуализует исследование речевых особенностей женщин-политиков, определяет их дискуссионность.

Прежде чем перейти к раскрытию исследуемой проблемы на конкретных примерах, следует кратко остановиться на теории вопроса. Необходимость преодоления мужского доминирования в общественной и культурной жизни в рамках языкознания нашла отражение, как уже отмечалось, в появлении феминистской критики языка или феминистской лингвистики. Задачи этого нового направления в языкознании заключались в преодолении сексизма языка с целью трансформации последнего [8, с. 98]. Действуя сообразно этим изменениям, женщины должны были отказаться от копирования речевой модели поведения мужчин, в результате чего в измененном языке конструкты поведения успешных мужчин и успешных женщин должны быть представлены наравне [12, р. 147]. Таким образом, феминистская критика языка исходила из того, что сознание личности, формы ее самопрезентации во многом структурируются особенностями языка. Дискуссионность речевого портрета женщины в политической практике отсылает к необходимости исследования основных различий мужской и женской речи. В частности, соглашаясь с теоретиками исследуемого вопроса, исследовавшими гендерные стереотипы речевой коммуникации еще в XX столетии, когда интерес общественности к данной проблематике только начинал формироваться, следует заметить, что женщинам в целом проблемно «быть услышанными», доводить высказывание до логического конца, так как в их речи реже встречаются утвердительные, конкретные и жесткие высказывания. Женская речь изобилует отговорками, эмоциональными выражениями («Боже мой», «Неужели» и т.д.), и уточняющими вопросами, свидетельствующими о неуверенной позиции говорящего [9, р.10]. В свою очередь, отказ женщин от подобного конструирования речевой практики может повлечь обвинения в маскулинной психологии. Однако, для женщины-политика использование исключительно «женской» речи, свободного стиля общения может иметь и обратный эффект: создать угрозу быть несерьезно воспринятой общественностью.

Необходимо отметить, что речевые особенности женщин-политиков, так же как и мужчин, формируются под влиянием общества, определенных социальных ожиданий, которые, в конечном счете, формируют различные и часто противоположные модели поведения. Так, для мужчин в большей степени характерна публичная вербальная коммуникация, целью которой является достижение и сохранение высокого статуса в обществе. В свою очередь, от женщин социум ожидает преимущественно гибкости, уступчивости, стремления избежать конфликта, в результате чего их коммуникация более мягкая и не соответствует мужским целям борьбы за сохранение своего положения в социуме. Указанные отличия выстраивания мужской и женской речевой коммуникации, сформированные под влиянием культуры и общества, были названы известным профессором лингвистики Д. Таннет термином «гендерлект» [17].

Речевой портрет женщины-политика конструируется на основании анализа примеров речевой коммуникации известных политических лидеров в силу того, что женщины редко играют определяющую роль в процессе принятия политических решений. Как следствие, анализ выступлений, дебатов с участием представительниц «прекрасного пола» предполагает исследование вербальной коммуникации политических лидеров, особенности которой призваны оказать необходимое коммуникатору воздействие на аудиторию. Речевой портрет женщин-политиков составляется на основании определенных категорий, подвергаемых оценке. Среди них можно назвать следующие:

1. чтение информации с листа / готовность произносить неподготовленную речь, вступать в открытый диалог со слушателями (как свидетельство 
высокого уровня речевой коммуникации и общего уровня культуры речи);

2. правдивое изложение информации / стремление «приукрасить» события;

3. использование властного и агрессивного стиля коммуникации / стремление к выстраиванию мягкого и гибкого диалога с аудиторией.

Анализ указанных характеристик и суммирование результатов позволяет составить адекватную картину коммуникативного уровня взаимодействия по линии «говорящий-слушатель» и речевого портрета коммуникатора.

В свою очередь, анализ выступлений политическихлидеров позволяет сделать вывод о наличии двух ведущих подходов к использованию гендерных характеристик в речи. Согласно первому из них, применение характерных особенностей речевой коммуникации мужчинами и женщинами служит задачам формирования определенного имиджа политика. В данном случае гендерный подход к участию в политических дебатах, выступлениях и т.д. осуществляется на основе учета говорящим настроения аудитории, в результате чего политик способен быстро менять собственную речь. В соответствии со вторым подходом, речевая тактика выстраивается коммуникатором на основании использования устойчивых стереотипов и метафор, присутствующих в женской речи, что обеспечивает адресность коммуникации, обращенной в большей степени к женской, либо к мужской аудитории [1].

В настоящей статье дискуссионные особенности речевого портрета женщин-политиков исследовались на основании выступлений А. Меркель и Х. Клинтон. Анализ речей немецкого государственного и политического деятеля А. Меркель, позволяет заключить, что в ее публичных выступлениях достаточно часто присутствуют сравнения, которые, однако, содержательны и соответствуют деловому стилю общения с аудиторией, избранному коммуникатором [16]. В речи немецкого канцлера также часто встречаются эпитеты, лаконично включенные в логику и общий официальный тон обращения к публике.

Помимо этого, А. Меркель часто обращается к перечислению, что, В свою очередь, позволяет политику влиять на логику слушателей, заставляя их верить в справедливость и обоснованность ее высказываний: «Wir brauchen auch Orte, die die Begegnung zwischen verschiedenen Gruppen fördern - Orte kritischer und kontroverser Diskussion, Orte des gesellschaftlichen Diskurses» [10]. Помимо перечислений, используемых в речи федерального канцлера Германии, следует отметить высокий уровень компетентности А. Меркель в социально-экономических вопросах, что подтверждается обращением политика к статистике, также вызывающее доверие аудитории. В этой связи можно заключить, что политические выступления А. Меркель относятся к речам «убеждающего» типа, что обусловлено главной чертой политического дискурса - борьбой за власть [3, с. 33-34]. Стремлению политика убедить аудиторию в своей правоте соответствует также заранее определенная структура коммуникации: первоначально канцлер Германии делает акцент на существующей проблеме и противоречии, к которой она желает привлечь внимание аудитории, приводит свои доводы и намечает пути выхода из сложившейся ситуации, что соответствует логике рассуждения в его классическом понимании.

Наличие сложно структурированных предложений в речи федерального канцлера объясняется тем, что каждое выступление первоначально подготавливается в письменной форме. При этом для текстов политических выступлений характерно использование предложений со сложноподчиненной связью: «Wenn man zudem berücksichtigt, dass die Wachstumsregionen der Welt im Wesentlichen außerhalb Europas liegen, dass in normalen wirtschaftlichen Zeiten 90 Prozent des weltweiten Wachstums auberhalb Europas stattfinden, dann weib man, dass Wachstum in Europa nur stattfinden kann, wenn die Wettbewerbsfähigkeit der europäischen Anbieter auch wirklich gegeben ist» [10]. В указанном примере подчинительная связь является многоуровневой, что позволяет сделать вывод о высоком уровне грамотности политика, способного легко воспроизводить в устной речи сложные синтаксические конструкции. В то же время, это служит задачам канцлера точно, последовательно и аргументировано излагать свою позицию публике.

В публичных выступлениях А. Меркель достаточно часто встречаются риторические вопросы, позволяющие сосредоточить внимание слушателей на основной идее выступления политика, а также воздействовать на восприятие аудитории посредством формирования определенных чувств по отношению к предмету выступления: «Was waren die Ursachen? Die Ursachen waren sicherlich vielfältig; Wem gehört der Zugang zu Ressourcen? ». Задача вызова эмпатии со стороны аудитории, стремление быть услышанной своим народом успешно решается А. Меркель посредством последовательной связи в речи целей и результатов: «Dazu brauchen wir mehr denn je den Mut zu neuem Denken, die Kraft, bekannte Wege zu verlassen, die Bereitschaft, Neues zu wagen, und die Entschlossenheit, schneller zu handeln, in der Überzeugung, dass Ungewohntes gelingen kann - und gelingen muss, wenn es der Generation der heute jungen Menschen und ihren Nachkommen noch möglich sein soll, auf dieser Erde gut leben zu können» [14].

Подводя итоги исследованию особенностей речевого портрета А. Меркель на основании анализа наиболее часто употребляемых лингвистических средств в речи политика, в частности, перечислений, сравнений, сложноподчиненных синтаксических конструкций, следует 
также отметить, что с точки зрения прагмалингвистического аспекта структуры дискурса для речи немецкого канцлера характерно использование комментирования, стратегий единения (в данном случае - немецкого народа), а также позитивного воздействия на аудиторию посредством похвалы, преднамеренного акцентирования достижений немцев и т.д., в целом характерных для выступлений любого политического деятеля. При этом в обращениях к своему народу у А. Меркель присутствует гендерная специфика: «lch danke den Frauen und Männern, die in unserem Land politische Verantwortung übernehmen, ganz besonders denen in den Kommunen. Sie - wie alle Menschen in unserem Land - vor Hass, Anfeindungen und Gewalt, vor Rassismus und Antisemitismus zu schützen, ist Aufgabe des Staates, eine Aufgabe, der sich die Bundesregierung besonders verpflichtet fühlt» [14].

Другим примером женщины-политика, публичные выступления которой позволяют сконструировать речевой портрет на базе анализа лингвистических особенностей, в рамках настоящей статьи была избрана Х. Клинтон американский политик и член Демократической партии. Выбор именно этого государственного деятеля США является не случайным, так как дискуссионные особенности речевого портрета женщин, являющихся активными участницами политической жизни, наилучшим образом прослеживаются при сопоставлении специфики коммуникации с общественностью А. Меркель и Х. Клинтон.

Если во внешнем облике исследуемых политических фигур прослеживается строгость, нейтральность, сдержанность, присущие образу публичной личности, то вербальная коммуникация их существенно отличается. Так, если речевой портрет А. Меркель в значительной степени определяется логичностью высказываний, использованием доказательной базы, призывами к единению, то образ Х. Клинтон, конструируемый в политических выступлениях политика, отличается большей женственностью, мягкостью и чуткостью по отношению к чаяниям рядовых граждан. Для достижения этого эффекта коммуникатор часто прибегает к намеренному смягчению фраз в выступлении, демонстрации некоторой неуверенности, эмоциональной выразительности в речи, способной оказать сильное воздействие как на женскую, так и на мужскую аудиторию.

Лингвистические особенности коммуникации X. Клинтон находят комплексное отражение в ее выступлении, посвященном атаке американского консульства в Бенгази. Это обращение к народу именно женщины-политика, сочувственное, проникновенное и насыщенное эмоциями, призванное доказать семьям, пострадавшим при атаке, истинность и глубину сочувствия и поддержки X. Клинтон: «Для меня это не просто политика, это личное... Я обнимала матерей и отцов, сестер и братьев, сыновей и дочерей, и жен, которые в одиночестве будут растить детей» [7].

Таким образом, лингвистический портрет Х. Клинтон в равной степени сочетает в себе черты политика и гендерные характеристики. Она по-женски стремится разделить с пострадавшими семьями всю боль утраты, не сдерживает эмоции. Как следствие, можно заключить, что в случае X. Клинтон обусловленные гендерной природой свойства речи служат задаче создания образа матери всего народа Соединенных Штатов, что является достаточно типичным для женщины в политике. Наряду с этим, в ряде выступлений Х. Клинтон успешно сочетаются гендерные особенности мужской и женской речи. В некоторых из ее выступлений присутствуют агрессивные и мотивирующие метафоры, в большей степени характерные для «мужских», нежели для «женских» текстов. Однако, следует принимать во внимание тот факт, что Х. Клинтон, будучи опытным политиком, способна имитировать маскулинный тип коммуникации при необходимости, в целом не свойственный стилю ее публичных выступлений. В качестве примера следует привести дебаты с участием Х. Клинтон, проходившие в штате Южная Каролина в январе 2016 г., где политик показала себя непримиримым борцом за улучшение уровня жизни американцев, права каждого гражданина Соединенных Штатов, независимо от пола, расы и возраста. Для этой цели X. Клинтон использовала жесткую лексику, четкое построение фраз: «We do have too much division, too much mean spiritedness. There's a lot we have to do on immigration reform, on voting rights, on campaign finance reform, but we need to do it together» [15]. Участие Х. Клинтон в дебатах подтвердило готовность политика использовать аргументированную лексику против своих политических оппонентов, отстаивать собственную точку зрения.

Наряду с этим на примере указанных дебатов, а также иных выступлений политика, необходимо отметить частое использование в начале высказываний Х. Клинтон вводных слов, например: «Well», «Sо» и проч., позволяющих выиграть, пусть и незначительное, время на конструирование дальнейшего высказывания. Несмотря на то, что по мнению некоторых исследователей частое использование подобных лексических единиц свидетельствует о нерешительности и неуверенности коммуникатора [13], следует признать, что в голосе Х. Клинтон, о чем свидетельствуют материалы прямых трансляций, а также записи выступлений политика, отсутствуют ноты сомнений, а использование вводных слов, в том числе - в рамках одного предложения («l mean... I think») позволяет ей не только убедить аудиторию в своей правоте, но и удержать ее внимание.

Резюмируя вышесказанное, следует отметить, что речевые особенности, позволяющие составить речевой портрет женщин-политиков на примере западных государственных и политических деятелей, не всегда являются обусловленными гендером. Учитывая немного- 
численность женщин, принимающих активное участие в политике, им приходится использовать все возможности вербальной коммуникации для того, чтобы быть услышанными аудиторией. В этой связи женщина-политик может использовать маскулинные особенности языка, опору на доказательность и логику, статистические данные (А. Меркель), являющиеся доминантами в ее публичных выступлениях. Однако, существуют примеры успешного сочетания гендерных особенностей языка, свойственных как мужчинам, так и женщинам в выстраивании коммуникации с гражданами (Х. Клинтон). От уровня понимания политиками ситуации, в которой необходимо использовать ту или иную коммуникацию, а в ряде случаев - сочетание женского и мужского стиля речи, зависит их успех, общественное признание и поддержка как в своей стране, так и за ее пределами.

ЛИТЕРАТУРА

1. Арустамян Р., Макурина М.А., Пирожкова И.С. Проявление гендерных особенностей в политическом дискурсе // Политическая лингвистика. Раздел 5. Зарубежный опыт. 2016. [Электронный ресурс]. - Режим доступа: URL: https://cyberleninka.ru/article/n/proyavlenie-gendernyh-osobennostey-vpoliticheskom-diskurse (дата обращения: 09.03.2021).

2. Коханская Е.А. Освобождение от стереотипа политики как поля мужского доминирования // Проблемы экономики и юридической практики. 2014. № 3. - C. 247-250.

3. Михалева 0.Л. Политический дискурс: Специфика манипулятивного воздействия. - М.: Либроком, 2009. - 252 с.

4. Мурясов Р.3. Категория рода в контрастивно-типологическом видении // Иностранные языки в условиях интернационализации образования и общества. Международная научно-прак. конф., посвященная 20-летию Российско-Таджикского (славянского) университета. Сборник докладов Душамбе. - Душамбе, 2016. - С. 172-180.

5. Саурбаев Р.Ж., Шагбанова Х.С. Речевые стратегии политического новостного дискурса на материале британской прессы: монография. - М.: Новый индекс, 2020. - 104 c.

6. Стернин И.А. Очерк английского коммуникативного поведения. - Воронеж: Истоки, 2003. - 183 с.

7. Хиллари Клинтон с плачем и криком отчиталась за теракт Бенгази перед конгрессменами: «Да какая разница?!» // Newsru.Com. 24.01.2013. [Электронный ресурс]. - Режим доступа: URL: https://www.newsru.com/world/24Jan2013/clinton.html (дата обращения: 09.03.2021).

8. Чурушкина А.Н. Гендерные исследования: из истории терминологии // Гуманитарные исследования. 2007. № 3. - С. 97-100.

9. Borisoff D., Merrill L. The Power to Communicate. Gender Differences as Barriers. - Illinois: Waveland Pr., 1998. - 151 p.

10. Eröffnung des Katholisch-Sozialen Instituts in Siegburg // Domradio.de. 04.05.2017. [Электронный ресурс]. - Режим доступа: URL: https://www.domradio.de/ themen/erzbistum-koeln/2017-05-04/mit-kanzlerin-und-kardinal-eroeffnung-des-katholisch-sozialen-instituts-siegburg (дата 0бращения: 09.03.2021).

11. Galliano G. Gender Crossing Boundaries. - Kennesaw State Univ., 2003. - 418 p.

12. Key M.R. Male/Female Language. - Metuchen, N.J. 1975. - 196 p.

13. Lakoff R. T., Bucholtz M. Language and Woman's Place. - New York: Oxford Univ. Pr., 2004. - 83 p.

14. Merkels Neujahrsansprache: «Die 20er Jahre können gute Jahre warden». 31 Dez. 2019. [Электронный ресурс]. - Режим доступа: URL: https://de.rt.com/inland/96308-merkels-neujahrsansprache-20er-jahre-konnen/ (дата обращения: 09.03.2021).

15. Read the Full Text of the Fourth Democratic Debate in Charleston // Time. 17.01.2016. [Электронный ресурс] - Режим доступа: URL: https://time.com/4183952/democratic-debate-full-text-hillary-clinton-bernie-sanders/ (дата обращения: 09.03.2021).

16. Rede von Angela Merkel zur Eröffnung der Hannover Messe // Voltaire Netzwerk. 24.04.2016. [Электронный ресурс] - Режим доступа: URL: https://www.voltairenet.org/article191538.html (дата обращения: 09.03.2021).

17. Tannen D. You Just Don't Understand: Women and Men in Conversation // SIGNS. T. 17. 1992. - P. 666-671. 